\title{
Use of the Judicial Section 9 Certification in the Free State
}

S J Meyer, MB ChB, MMed (Psych)

M Slabber, MB ChB, MMed (Psych)

Department of Psychiatry, University of the Free State, Bloemfontein

P H J J van Rensburg, MB ChB, MMed (Psych), MD PO Box 13827, Noordstad, Bloemfontein, 9302

M Nel, BA, BA Hons, MMedSC

Department of Biostatistics, University of the Free State, Bloemfontein

A direct referral system for referring persons who perpetrate a crime while suffering from a mental illness has evolved between the office of the Director of Public Prosecution (DPP) in the Free State, and the Free State Psychiatric Complex (FSPC) over the years. The efficiency and impact of this direct referral system have never been quantified. This study found that this alternative system is uncomplicated, functions quite effectively with a minimum of inappropriate referrals, and contributes greatly towards decreasing the workload of the judicial as well as the psychiatric system.

A direct referral system of referring persons who perpetrate a crime while suffering from a mental illness has evolved between the office of the Director of Public Prosecution (DPP) in the Free State, and the Free State Psychiatric Complex (FSPC) over the years. The efficiency and impact of this direct referral system have never been quantified.

In terms of the Criminal Procedure Act 51 of 1977, 1,2 an accused may be referred to a psychiatric forensic unit by the court for a 30day observation period if it is suspected that he might have been suffering from a mental illness at the time of the crime. The observatus is referred in terms of Sections 77 and 78 of the act to determine trialability and accountability. A full organic work-up is done and regular interviews are conducted by the members of a multiprofessional team. A final report is then compiled by the psychiatrist and submitted to the court. This process is very labour inten- sive, time consuming and expensive. If it is found that the observatus was indeed suffering from a mental illness or defect at the time of committing the crime, $\mathrm{s} /$ he can then be referred for admission to a state mental institution as a state patient.

\section{Laws}

Section 78 of the Criminal Procedure Act of 1977 provides that a person who commits an offence and who at the time of commission suffers from a mental illness or defect which renders him or her incapable of understanding the wrongfulness of his or her act or of acting in accordance with such appreciation, is not criminally responsible for that act. As in the case of section 77, the court may refer an accused for observation. However, when an allegation of criminal incapacity is made on the grounds of mental illness or mental defect, the accused must be referred for observation if there is a reasonable possibility that the accused suffers from a mental illness or mental defect. There exists in our law a presumption that everyone is sane, and if an accused pleads insanity, the burden of proof lies on him or her to prove it.

The Criminal Procedure and Amendment Acts afford the courts several options.

1. In a case where the accused is charged with murder, culpable homicide, rape or another charge involving serious violence, or if the court considers it to be necessary in the public interest that the accused be: (i) detained in a psychiatric hospital or a prison pending the decision of a judge in chambers in terms of section 29 (1) (a) of the Mental Health Act of 1973 (Act No. 18 of 1973); (ii) admitted to, detained and treated in an institution stated in the order in terms of chapter 3 of the Mental Health Act of 1973 (Act No. 18 of 19731, pending discharge by a hospital board in terms of section 29(4A)(u) of that Act; (iii) treated as an outpatient in terms of section 7 of that Act pending certification by the superintendent of that institution stating that he or she need no longer be treated as such; (iv) released subject to such conditions as the court considers appropriate; or ( $v$ ) released unconditionally.

2. In any case other than a case contemplated in subparagraph 1 , 
the court may order that the accused: (i) be admitted to, detained and treated in an institution stated in the order in terms of chapter 3 of the Mental Health Act of 1973 (Act No. 18 of 1973), pending discharge by a hospital board in terms of section 29(4A)(a) of that Act; (ii) be treated as an outpatient in terms of section 7 of that Act pending certification by the superintendent of that institution stating that he or she need no longer be treated as such;' (iii) be released subject to such conditions as the court considers appropriate; or (iv) be released unconditionally.

Owing to the fact that many of the patients are ill at the time of the crime and still without insight into their mental condition, management in terms of sections 3 and 7 is impractical. This is where a section 9 certification is an appropriate alternative as it permits involuntary treatment of a patient who might otherwise refuse treatment. In a patient referred for a 30-day observation period charged with a lesser crime, the psychiatrist can recommend that the charge be withdrawn and the patient be referred as a state patient. The DPP's office can then decide to withdraw the charge on condition that the accused be admitted for treatment in terms of section 9 of the Mental Health Act.

The seriousness of the crime influences the decision as to whether a patient will be admitted in terms of section 28 or section 9 of the Mental Health Act. The main difference between the two is the manner in which an application for discharge is made once the patient has been treated and rehabilitated. If the detention was done in terms of section 28 of the Mental Health Act, then the patient can only be released after an application has been lodged with the DPP's office, which then decides whether the patient is to be discharged by the hospital board or by a judge in chambers. If a patient was admitted in terms of section 9 of the Mental Health Act he can be discharged once the multiprofessional team is convinced that he has been sufficiently treated and rehabilitated. All patients admitted as state patients are treated for their mental illness. Patients attend a therapeutic programme involving group activities, occupational therapy, as well as insightoriented therapy under the guidance of the multiprofessional team.

\section{The alternative system}

The alternative system evolved during the early 1980s in order to try and reduce the number of observati. Initially the patients were all referred for a short court evaluation, but in time telephonic consultations and direct referrals became more frequent. The system functions along the same lines as other forensic referrals with the major difference being that the accused is not sent for an obser- vation period. This is where regular communication and joint meetings between the parties involved is of extreme importance as the collaboration between specialists in these co-dependent fields contributes to significant savings in time and money. In a case where the suspect is clearly suffering from a mental illness, and a minor crime is involved, the DDP's office can confer with a psychiatrist at the forensic unit. The charge is then withdrawn on condition that the patient be admitted to the FSPC in terms of section 9 of the Mental Health Act, and treated for his condition. Where a charge is laid and then withdrawn on the grounds of mental illness or defect, it is locally referred to as a judicial section 9 admission (Fig. 1).

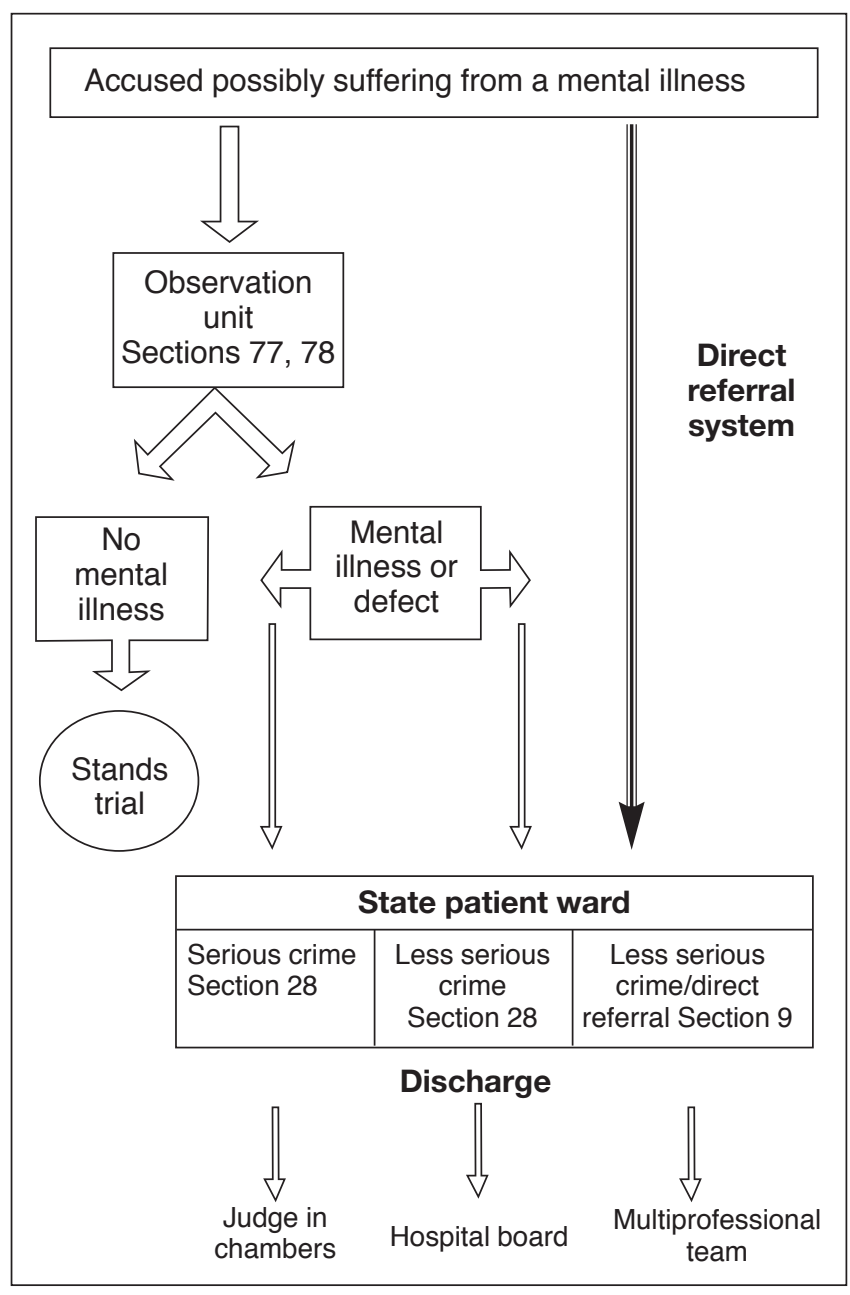

Fig. 1. Schematic representation of direct referral system.

This system is only used where there is no doubt that the accused is suffering from a mental illness. If there is any doubt, the accused will be referred for the 30-day observation period, or will be evalvated by a psychiatrist during a short court evaluation after which a decision is taken as to which route to follow. In the event of a 
patient admitted in terms of section 9, but found not to be suffering from a mental illness the public prosecutor's office is notified, a report is prepared by the psychiatrist, the charge reinstated and prosecution continued.

In some areas an adversarial relationship has evolved between prosecutors and the psychiatric services. This has mainly been due to poor communication and lack of knowledge concerning the procedure and difficulties experienced by the other party. This state of affairs is extremely counterproductive and could turn a simple request for information into a bureaucratic nightmare. It also adds to the burden of the forensic psychiatric units, as well as the already overburdened judicial system.

At FSPC we are very fortunate in having a senior advocate from the DPP's office who attends weekly ward rounds with the multiprofessional team of the state patient wards. At these rounds all new admissions are seen and all potential leaves and discharges discussed. The advocate is notified in advance of the patients to be seen and brings along documents relevant to the case. Any outstanding paperwork that might have been delayed in the system is noted and problems concerning specific certification procedures or magisterial regions are discussed. This is also where any inappropriate judicial section 9 certifications are discussed; arrangements can then be made to have the charge reinstated and prosecution continued. The time invested by the DPP's office and the psychiatric team pays off in a decrease in number of enquiries, reports and letters, and it speeds up the administrative process. All involved also have the opportunity to become fully informed about the facts and details of every case.

We believe that with good communication between the judicial system and the mental health institutions, this system could benefit other areas of the country that also suffer from a shortage of manpower and insufficient funds. The financial implications might be even greater if the reduction of time in court, reduced administrative costs, and time spent in custody between observation and court appearances is taken into account. It would further help to alleviate the burden on the judicial system and decrease waiting time for court appearances.

\section{Study}

\section{Aim of the study}

The aim of the study was to look at the impact of the judicial section 9 admission on the patient load and cost savings at the forensic observation unit of Oranje Hospital. The study used the admis- sion data collected over a 6-month period at the state patient and forensic wards at Oranje Hospital, and therefore reflects only the savings at this hospital. It does not include the reduced court times, and time in custody awaiting trial. As a retrospective study, the researcher had no influence on the data as recorded.

\section{Sample}

Files of all patients admitted to the state patient ward during the 6 month period January 2001 to June 2001 were reviewed to determine the section in terms of which they were admitted, demographic data, charges, and the psychiatric diagnoses.

Inclusion criteria were: (i) all State patients admitted in terms of section 9; (ii) all observati admitted to the forensic unit; and (iii) patients admitted from 1 January 2001 to 30 June 2001.

Exclusion criteria were: (i) patients referred in terms of section 28; (ii) re-admissions in terms of section 38B; and (iii) observati admitted to Grootvlei Prison for observation.

Observati deemed to be extremely dangerous are sent to Grootvlei Prison and regular evaluations by psychiatrists are conducted there. During the study period four persons were admitted to Grootvlei but because of different circumstances they were excluded from the cost calculations. Ethics committee approval was obtained before commencement of the trial.

The file review was also undertaken to evaluate the quality of direct referrals. Files of all the patients admitted to the forensic observation unit over the same period were used to determine the average duration of an observation, and to try and estimate the cost per observation. Admission registers and patient files were cross-referenced to ensure that all the admissions during the study period were taken into account, and that the data corresponded. All of the section 9 admissions to the state patient ward were also cross-referenced with the observation unit admissions to establish the number of admissions who had undergone an observation period (observation section 9), and the number directly referred as judicial section 9 patients.

\section{Results}

\section{Route of referral}

During the 6-month period 80 state patients were admitted to the Free State psychiatric complex. Thirty-eight of these admissions were in terms of section 28 (serious offences), and 1 patient was admitted in terms of section 38B (re-admission). The other 41 
patients were admitted in terms of section 9. Only 6 of these had been seen at the forensic observation unit for lesser crimes and the other 35 were direct referrals from the courts where the alleged crime was less serious and the patients appeared to be suffering from a mental illness. This accounted for $85 \%$ of the section 9 admissions. This implies that $85 \%$ of the lesser crimes perpetrated by psychiatric patients could possibly be dealt with successfully through use of the judicial section 9 system.

\section{Cost}

The cost of keeping an observatus at the forensic unit was previously estimated at R30 000 per observation period of 30 days. If the 34 patients referred directly had to be referred to the forensic observation unit before admission, it would have cost an extra R 1020 00, or a possible R2.04 million per year. This is only the direct cost of operating the forensic observation unit and does not even start to take into account the cost to the judicial system, cost of the time spent awaiting trial, and transport and costs to the SA Police Services. This also does not take into account the fact that discharge of the judicial section 9 patients can take place as soon as they have been rehabilitated, without all the extra paperwork.

\section{Charges}

All accused with serious charges including assault with intent to do grievous bodily harm are sent for observation after consultation with the DPP's office, and if found to be suffering from a mental illness are then referred as state patients in terms of section 28 of the Mental Health Act. It was therefore important to confirm that no serious violence was seen in the range of charges brought against patients admitted directly in terms of section 9. Some of the patients had more than one charge, e.g. assault and malicious damage, accounting for the 46 charges in 41 patients. No patient with a serious charge was admitted during the study period (Table I).

Table I. Charges against judicial section 9 patients $(N=46)$

\begin{tabular}{lc}
\hline Charge & $N(\%)$ \\
\hline Housebreaking and theft & $10(24.4)$ \\
Assault & $20(48.8)$ \\
Malicious damage & $8(19.5)$ \\
Attempted rape & $2(4.9)$ \\
Arson & $3(7.3)$ \\
Trespassing & $2(4.9)$ \\
Public indecency & $1(2.4)$ \\
\hline
\end{tabular}

\section{Diagnoses}

Of the 35 direct referrals only 1 patient was found not to have been suffering from a mental illness. This individual frequently abused illegal substances and would assault his parents to obtain money for his habit. During initial evaluation after arrest he could have been intoxicated and confused and therefore warranted referral for evaluation. On full psychiatric evaluation after admis sion, however, he was not found to be suffering from a mental illness. The case was discussed with the representative of the DPP's office, the charge reinstated, and the person was re-arrested and prosecuted. Roughly $40 \%$ of the observati had no discernable mental illness, and the diagnosis most often made was schizophrenia (Table II).

Table II. Comparative diagnoses ( $N(\%)$ )

\begin{tabular}{|c|c|c|}
\hline Diagnoses & $\begin{array}{l}\text { Observati } \\
(N=67)\end{array}$ & $\begin{array}{l}\text { Section } 9 \text { patients } \\
\qquad(N=41)\end{array}$ \\
\hline No mental disorder & $26(40.3)$ & $1 \quad(2.4)$ \\
\hline Schizophrenia & $27(40.3)$ & $20(48.8)$ \\
\hline Mental retardation & $4 \quad(6)$ & $1(2.4)$ \\
\hline Bipolar disorder & 2 (3) & $6(14.6)$ \\
\hline Organic personality disorder & $2(3)$ & $2(4.9)$ \\
\hline $\begin{array}{l}\text { Psychoses not otherwise } \\
\text { specified }\end{array}$ & $2(3)$ & \\
\hline Dementia & $1(1.5)$ & \\
\hline Antisocial personality disorder & r $1(1.5)$ & \\
\hline $\begin{array}{l}\text { Psychoses due to general } \\
\text { medical condition }\end{array}$ & 2 (3) & $4 \quad(9.8)$ \\
\hline Schizo-affective disorder & & $2(4.9)$ \\
\hline $\begin{array}{l}\text { Mood disorder due to } \\
\text { general medical condition }\end{array}$ & & $1(2.4)$ \\
\hline Substance-induced psychosis & & $4(9.8)$ \\
\hline
\end{tabular}

\section{Discussion}

During the study period only 1 patient was admitted inappropriately as a judicial section 9. This in itself speaks volumes for the efficacy of the direct referral system as well as the knowledge of prosecutors who often find themselves fairly isolated in the rural areas.

Given the limited resources and lack of manpower, specialised units such as the forensic observation unit have become increasingly strained under a growing burden of patients sent for observation, and some of these units already have waiting lists for admissions. Specialists working at these units need to see the 
observati on a regular basis to ensure accurate diagnoses, and therefore cannot deal with high numbers of observati. As the behaviour of the accused and facts concerning the crime are crucial in evaluating accountability, the police docket is a vital part of the evaluation. Sadly, it is often a delay in obtaining these documents that slows the whole process down unnecessarily.

We believe that regular quality contact between the DPP's office and the multiprofessional forensic psychiatry team is the key to the success of the system of the judicial section 9. The fact that only 1 of the 35 admissions was returned to be prosecuted is a testimony to the efficiency of this co-operative system. The open line of communication not only speeds up the process which could otherwise have been tedious, but also helps solve frustrating misunderstandings. The DPP's office often fulfils the role of mediator between the forensic unit and the court as the advocate has insight into the difficulties and specific needs of both parties. The few hours spent weekly at the ward rounds ensure that legal processes run smoothly, which in turn means that no patients are discharged too early or kept too long. As many of the regulations governing state patients are guided by law, the advocate is also a valuable source of advice to the doctors concerning liability, rights of patients and staff, court decisions, and procedure.

We also believe that the time spent at these team rounds at the state patient wards make it possible for a parallel system such as the judicial section 9 to exist without the danger of ignorance leading to infringement of patient rights. At the same time this system expedites admission of patients who are clearly in need of treatment and prompt treatment normally means earlier remission and reintegration into the community. A direct saving in excess of R2 million per year as well as savings in terms of time and other valuable resources is well worth the effort invested by both departments.

\section{References}

Criminal Procedure Act of 1977 (Act No. 51 of 1977)

2. South African Law Commission. The declaration and detention of persons as state patients under he Criminal Procedure Act, Act 51 of 1977, and the discharge of such persons under the Mental Heal h Act, Act 18 of 1973, including the burden of proof wi h regard to he mental state of an accused or convicted person. Pretoria: South African Law Commission, 1996 3. Mental Health Act, 1973 (Act No. 18 of 1973). 